\title{
6
}

\section{Agile Purpose: Overcoming Bureaucracy}

\section{Carlos Rey, Nuno Pitta, Donatas Ramonas, and Phil Sotok}

As the twenty-first century progresses, marked by a staggering increase in change, volatility, and complexity, many executives are having trouble resolving the tension between innovation and operational discipline. Some blame hierarchical structures for slowing down the decision-making process, generating excessive bureaucratization, and hindering innovation. This challenge is so difficult that it has led to several decades' worth of management experiments that completely challenge traditional organizations-democratic companies, podularity, liberated organizations, holacracy—but none of them are offering a clear answer. ${ }^{1}$ In general terms, these supposed 'solutions' do not always fit within the natural development of an organization and its institutional configuration, and moreover, by themselves they are unable to solve the problems of bureaucracy. ${ }^{2}$

\section{Rey $(\bowtie)$}

Universitat Internacional de Catalunya,

Barcelona, Spain

e-mail: carlosrey@uic.es

N. Pitta • P. Sotok

DPMC, Barcelona, Spain

e-mail:n.pitta@dpmc.es; psotok@dpmc.us

D. Ramonas

CRC Consulting, Vilnius, Lithuania

e-mail: donatas.ramonas@crc.lt 
More recently, movements born from concepts such as 'agile organizations'3 are exploring new ways to develop adaptable and responsive structures. But what is commonly underestimated in their practical development is that structures, per se, do not create the energy or sense of meaning that a dynamic marketplace requires. It is simply not enough to challenge traditional structures in order to gain agility in organizations. Indeed, the common denominator we find in successful cases of highly adaptive organizations is a high sense of purpose.

Think about some of the successful 'alternative organizations' that have been studied over recent years: Gore, Patagonia, Morning Star, and Zappos. As we see things, the key to their success does not come only from eliminating hierarchies, but from combining alternative structures with an overarching sense of purpose. All of these companies have served as good examples of purpose-driven organizations. Gore and Patagonia are commonly used as exemplars of humanistic management. ${ }^{4}$ Morning Star, the tomato processing company in California that has 'no bosses', has been recognized by researchers as a highly purpose-driven organization, ${ }^{5}$ as is Zappos, which claims that its purpose is 'to deliver happiness to the world'. ${ }^{6}$ It is no coincidence then that researchers are finding a high sense of purpose as core to successful and highly adaptive organizations. ${ }^{7}$ It is seen also at the foundation and creation of shared leadership. ${ }^{8}$ This is why loss of purpose is frequently cited in cases of adaptive failure (e.g. Nokia ${ }^{9}$ ). Likewise, many attempts to create agile organizations fail because of a purposeless and disengaged workforce.

Hierarchy brings challenge (as with any human organization), but hierarchy is not the main problem. The underlying problem is that companies try to create more adaptative organizations by means of organizational forms that are themselves not structured around purpose. What companies need, rather, in order to gain agility in the new 'purpose economy', ${ }^{10}$ is not the unnatural introduction of alien practices, but organic systems and structures that fit within their existing institutional configuration and purpose. ${ }^{11}$ Purpose and agility have a fundamental interrelationship that requires a renewed understanding of traditional management practices.

Based on our research and consulting work, this chapter will offer an integrated view, one we refer to as 'agile purpose': the development of agile organizations by means of purpose-driven structures. First, we will show how purpose can be deployed into the management structure through the use of missions and further, of how to combine missions with forms of organizational agility in order to unleash the full potential of purpose. 


\section{Purpose and Missions}

Activation of purpose through a compelling mission is considered by experts as fundamental for 'unleashing the power of purpose'. ${ }^{12}$ This can be explained through the interplay of four basic management tools: missions, competences, objectives, and processes (see Table 6.1). The last three-processes, objectives, and competences-constitute the basic 'operating system' of a company. They represent the 'what and how' and relate to our tasks, achievements, and behaviors.

However, for purpose to prevail, it requires 'a new organizational form' ${ }^{13}$ that moves beyond the traditional management tools of 'what and how'. It demands a form 'that does not presuppose homogeneity of background or tasks'. Purpose is like a new 'hardware' that demands a new 'software'. When management systems fail to support the development of purpose, then its development suffers because 'the systems ordinarily prevail'. ${ }^{14}$ Many recent research findings are pointing in this direction.

Consider, for example, the research on goal framing. This theory argues that management systems based on objectives undermine the development of purpose, as they tend to focus on extrinsic gain and neglect the pro-social goals necessary for purpose development. ${ }^{15}$ This is consistent with other recent research that shows the tendency of target setting to focus inward and discount external information, ${ }^{16}$ promoting the 'dark side ${ }^{17}$ of goal setting that can motivate unethical behavior, ${ }^{18}$ or increase the negative effect of goaloriented management in turbulent environments. ${ }^{19}$

In a way, this limitation is intuitive. Just as we know one can complete a lot of tasks without meeting the given objective, one can meet various objectives without fulfilling any purpose. This is something we have seen, for example, in the damage certain financial companies and institutions caused by incentivizing their managers to achieve objectives that systematically sowed the seeds of the financial crises and subsequently damaged the entire world economy.

Many experts insist that the solution is not to eliminate objectives, but rather to develop a new 'cognitive/symbolic management' approach that fosters the operationalization of purpose in organizations. ${ }^{20}$ As we see it, this new

Table 6.1 Basic management tools

\begin{tabular}{ll}
\hline Management tools & Related to \\
\hline Missions & Impact \\
Competences & Behavior \\
Objectives & Achievements \\
Processes & Tasks \\
\hline
\end{tabular}


cognitive/symbolic management approach is grounded in the implementation of missions.

\section{Corporate, Team, and Individual Missions}

At the corporate level, purpose and missions are frequently used as interchangeable terms as both reside in the domain of 'why'. However, purpose and missions can also be quite different in substance. Purpose is generally described broadly, usually in one or two concepts. Missions are typically more concrete, reflecting the desired impact a company professes to its main stakeholders (customers, employees, shareholders, etc.). ${ }^{21}$

Missions are a form of externalization of purpose that make explicit the impact we have on others. ${ }^{22}$ Missions help to turn purpose into a practical reality, solidifying purpose into specific commitments to specific beneficiaries. Missions, at the collective or individual level, answer the questions: What are the main beneficiaries of our/my job? What is the impact we/I want to have on them?

Think about the videos that many organizations offer, showing their impact on society. When companies are true to their purpose, these videos are a great source of energy and motivation. Missions are like these videos, telling every employee and team what they specifically do for others: a colleague, a friend, a customer, a supplier, or society. Missions are the sum impact that each employee makes for the other in their sphere of influence.

In our experience, the use of missions can be a very powerful and effective management tool, but only when its practice meets three fundamental conditions. First, missions must emanate from the intersection between personal and organizational purpose. They are not simply an intellectual construct, or a technical design. Missions come alive from purpose as they arise from the domain of the new logic of purpose. As a result, missions have little to no effect when developed in contexts dominated by the old logic of management. This is the fundamental reason why they have been ineffective in so many companies. ${ }^{23}$ They are being used by companies that are not truly purpose driven. It is like having a software program that does not match the hardware. You can download it, but you cannot install it. If the company is not true to its purpose, missions are irrelevant. But if the company is true to its purpose, missions become of extreme importance. 
The second condition is to ensure that the corporate missions are aligned with the intra-organizational missions (team and individual). As research has consistently demonstrated, the widespread practice of defining missions only at the corporate level is insufficient in helping employees understand how missions affect them personally, in their daily activities. ${ }^{24}$ The corporate purpose needs to be deployed in the form of missions to every individual, providing a consistent framework for organizational alignment. ${ }^{25}$ Expanding the presence of missions, as we see it, is a philosophy based on the principle of subsidiarity: matters should be handled at the most decentralized level. This principle, observed in the social and political arenas in many different cultures and countries, has been traditionally neglected in the theory of management and 'it has rarely been applied to business organization'. ${ }^{26}$ However, it is the principle that resides in the new quest for purpose-driven organizations, as 'embedding subsidiarity in purpose would give employees the autonomy and support, when necessary, to make decisions that are purpose-driven'. ${ }^{27}$ Intraorganizational missions make explicit to every individual and every team how their contribution impacts the company's mission[s], and ultimately its purpose (see Fig. 6.1).

The third condition is that missions must be evaluable. Many organizations take great effort to define their missions at a corporate, team, and individual levels, yet they fail to establish respective mechanisms to measure their attainment. When this happen, missions fall into the 'inspirational' category,

\section{Purpose UNITY}

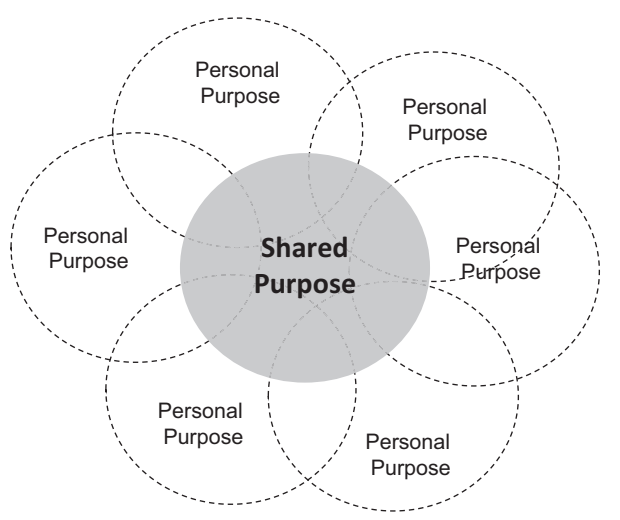

Fig. 6.1 Interplay between unity and alignment

\section{Missions Alignment}

Corporate missions<smiles>C1CC1</smiles>

Team missions<smiles>C1=CC1</smiles>

Individual missions 
becoming a public relations exercise or mere rhetoric. They lack having a tangible impact on its management. Implementing purpose by means of missions requires the discipline of measuring their performance to purpose. This is the case in Semillas Fitó, an international seed company based in Barcelona. They define their missions at the corporate and team levels and then use what they call 'mission scorecards' to monitor the progress of each mission relative to their corporate purpose. ${ }^{28}$

\section{Aligned Autonomy}

Missions constitute a fundamental tool to foster the equilibrium between alignment and autonomy. As missions emanate from purpose, they represent a 'higher level' of alignment than competences, objectives, or processes. By creating alignment through missions, organizations give structure to individual freedom, thereby increasing their capacity to see and respond to change. This alignment further helps both teams and individuals adapt and reconfigure their objectives and competences in a coordinated manner, without losing alignment to the company's purpose. Consider, for example, the case of Spotify. Along with the company's mission, each team has a long-term mission that is aligned with Spotify's overall mission as well as coordinated with other teams' missions. Through the alignment of missions, they create 'loosely coupled and tightly aligned' teams. As they say 'it is kind of like a jazz band. Although each musician is autonomous, they listen to each other and focus on the whole song together. That is how great music is created'. With missions, Spotify provides a combination of high levels of autonomy and alignment, while leaving freedom for processes, objectives, and competences to be reconfigured by individuals. They do this without losing the overall alignment to their purpose. This is called 'aligned autonomy'. ${ }^{29}$

Morning Star applies a similar approach. Their corporate mission is deployed in hundreds of personal missions - defined by its full-time and parttime employees. 'Missions are the cornerstone of Morning Star's management model' where 'you are responsible for the accomplishment of your mission and for acquiring the training, resources, and cooperation that you need to fulfill your mission'. By defining missions in this way, Morning Star has gained an overarching framework that makes possible 'shifting the focus from ruledriven compliance to peer-negotiated accountability'. ${ }^{30}$

The capacity of missions to align organizations at a 'higher level' can also be seen in the highly complex organizations found in healthcare, where processes 
are systematized and interdependent. Missions at different levels and functions (e.g. physicians, nurses, and managers) can support each group's 'understanding of the others' mission, helping the integration of work and enhancing a shared sense of purpose. ${ }^{31}$ In this way, the coordination of missions overcomes the limitations of bureaucracy, giving more freedom to act within hierarchical structures. Take the case of Biok, for example, a leading cosmetics company in the Baltic region. They define missions at various levels of the company which helps them to move forward with new products into new markets with much more speed, while staying true to the spirit of the purpose along the way. ${ }^{32}$ Another case is that of the multinational oil company Repsol. They evaluate their alignment to missions - deployed by each departmentby examining any conflicting issues (e.g. between sales and operations) and turning those into joint objectives. This practice facilitates cooperation, and even sacrifice when required. By promoting alignment at a 'higher level' of purpose, the coordination of missions helped Repsol to break silos and avoid escalating conflicts, changing drastically the levels of communication among departments, middle management, and employees. ${ }^{33}$

Missions alignment can also guide the deployment of objectives, incorporating more agile and adaptive practices. We are used to understanding the alignment of objectives as a top-down process. But in reality, there are other ways to align objectives that can be more productive and flexible. These are, for example, peer negotiation (where objectives get discussed by teams) or bottom-up (where lower-level employees become the primary source of setting objectives). With missions, whether arrived at from top-down, bottomup, or peer-to-peer, these practices are not exclusive but mutually reinforcing. Consider the case of the sales force of Alpha Omega, in Israel. In the overall context of missions alignment, base-line employees propose their objectives, then discuss in small groups with peers, and finally, agree with managers who aggregate and coordinate the objectives. ${ }^{34}$ This is the case as well for NalonChem, where a similar missions alignment process 'helped to reduce the time of setting objectives by half', ${ }^{35}$

Finally, missions alignment helps to connect the organization to its stakeholders by setting objectives in what is called an 'outside in' approach. ${ }^{36}$ This approach considers actual market trends and needs, rather than taking a company's prior year performance as the starting point. Thus, by combining missions with data from the marketplace, goals become more ambitious and adjustable, providing guidance, autonomy, and orientation for teams and individuals to define better objectives. ${ }^{37}$ 


\section{Agile Structures and Purpose}

From a practical point of view, organizations can realize the benefits that emerge when their people are both autonomous and aligned in what we call the 'agile purpose chart'. It shows the various outcomes that occur when we integrate missions into operational reliability and adaptability. ${ }^{38}$ Reliability refers to undertakings such as obtaining expected results, adjusting standards, meeting budgets, managing risk, following strategy, and so on, while adaptability refers to the autonomy of our work, the capacity for innovation, the ability to adapt to customer needs, or the improvement of processes, to name a few. When team and individual missions are combined with reliability and adaptability, we set the stage for a different kind of organizational structure. One that simultaneously develops and integrates into a holistic model. This model includes the concurrent combination of four hierarchical and selfmanaged organizational forms: governance hierarchy, management hierarchy, self-managed teams and self-managed networks (see Fig. 6.2).

Today, most companies continue to define themselves primarily by hierarchical designs. However, in reality, usually all four are present in purpose-driven companies. These four designs are indeed natural developments of purposedriven organizations. The military is a good example of this. Despite their hierarchical structures, their collective high sense of purpose forms itself into a

AGILE PURPOSE CHART

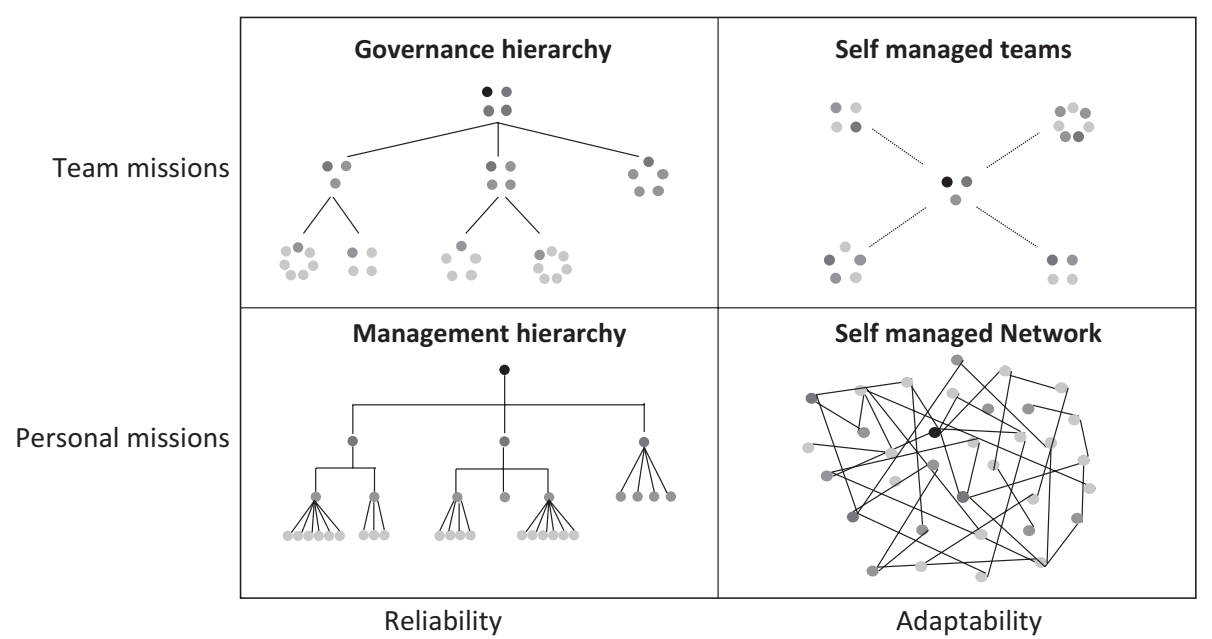

Fig. 6.2 Illustration of an agile purpose chart 
well-orchestrated network of self-managed teams. ${ }^{39}$ Or in the case of Wikipedia: although it is a self-managed network of individuals, it requires some form of hierarchy for 'legitimate authority' to govern the purpose of the organization. ${ }^{40}$ In our experience, the model we present here helps to outline the actual potential residing in purpose-driven organizations. In short, it provides a framework in which each company can find its natural place, combining the hierarchical and non-hierarchical forms to best suit its purpose and institutional requirements. Every company needs to find its particular equilibrium in the use of the four designs mentioned above, and avoid the least productive scenarios residing on the fringes.

Through the framework, we have seen companies dramatically increase their ability to adapt to change, making profound transformations while, at the same time, reinforcing their commitment to the outlined purpose. For Jimenez Maña, the automobile spare parts company in Andalusia, this was indeed the case. The company initiated a significant transformation to its business by re-focusing efforts and activities around its true comparative advantage. It did so without the elimination of hierarchies. Instead, they combined hierarchical and self-managed structures, and facilitated their coordination and consistency through the use missions, which served as their source of overall alignment. To this end, the company employed self-managed teams and networks as a primary way of organizing their operations. Questions such as the definition of the strategy, the coordination of missions, or the establishment of compensation are addressed through the governance and management hierarchy. ${ }^{41}$

In our experience, the agile purpose chart increases an organization's ability to sense and react to change without losing its alignment to purpose. Such a model provides a legitimate source of authority to individuals and teams, empowering them not by the chain of command but primarily by purpose. It offers enormous potential for the development of organizations, helping to solidify purpose while enhancing motivation, adaptability, and agility. It is an answer to the question that organizational theorists struggle with when confronting a world of relentless change, ferocious competition, and unstoppable innovation: 'How do we build organizations that deserve the extraordinary gifts that our employees bring to work?' ${ }^{2}$ The agile purpose chart helps people find their 'right place' in organizations by allowing them to express their personal purpose at work. This means giving individuals what is called 'freedom within a framework', allowing them the space to breathe, grow, and evolve within the company's changing needs. ${ }^{43}$

The agile purpose chart, in the broadest sense, provides a much deeper view of the organization as well as the person. Here each employee feels and acts as 
the true protagonist of their work, and managers know how to handle, with skill, the delicate balance that exists between their role as leaders and their duty as bosses. Missions ultimately help incorporate the new logic of purpose that views employees from a transcendent perspective, capable of acting for reasons other than the mere satisfaction of their own needs. This now becomes the new point of departure, that is, when we see the organization through the lens of purpose we ultimately see the person through this same lens. Their reason for being shines because they are part of a high-purpose environment where they can more easily respond to their calling and give of themselves, freely and meaningfully in concert with others, toward a common end.

\section{Notes}

1. Gulati, R. (2018). Structure that's not stifling. Harvard Business Review, 96(3), 68-79.

2. Hamel, G., \& Zanini, M. (2016). Top-down solutions like holacracy won't fix bureaucracy. Harvard Business Review.

3. Rigby, D. K., Sutherland, J., \& Noble, A. (2018). Agile at scale. Harvard Business Review.

4. https://vimeo.com/114733511. Retrieved September 27, 2018.

5. Hamel, G. (2011). First, let's fire all the managers. Harvard Business Review, 89(12), 48-60.

6. Forbes 2013/11/04/. Retrieved from https://www.forbes.com/sites/skollworldforum/2013/11/04/gamechangers-the-worlds-top-purpose-driven-orga nizations/\#73ed2dc377b6

7. Fjeldstad, Ø. D., Snow, C. C., Miles, R. E., \& Lettl, C. (2012). The architecture of collaboration. Strategic Management Journal, 33(6), 734-750.

8. Carson, J. B., Tesluk, P. E., \& Marrone, J. A. (2007). Shared leadership in teams: An investigation of antecedent conditions and performance. Academy of Management Journal, 50(5), 1217-1234.

9. Chevreux, L., Lopez, J., \& Mesnard, X. (2017). The best companies know how to balance strategy and purpose. Harvard Business Review.

10. Hurst, A. (2016). The purpose economy: How your desire for impact, personal growth and community is changing the world. Elevate Publishing.

11. Mackey, J., \& Sisodia, R. (2014). Conscious capitalism: Liberating the heroic spirit of business. Harvard Business Review Press.

12. Ibidem.

13. Adler, P. S., \& Heckscher, C. (2018). Collaboration as an organization design for shared purpose. In Toward permeable boundaries of organizations? (pp. 81-111). London: Emerald Publishing Limited.

14. Laloux, F. (2014). Reinventing organizations: A guide to creating organizations inspired by the next stage in human consciousness. Brussels: Nelson Parker. 
15. Birkinshaw, J., Foss, N. J., \& Lindenberg, S. (2014). Combining purpose with profits. MIT Sloan Management Review, 55(3), 49.

16. Aranda, C., Arellano, J., \& Davila, A. (2017). Organizational learning in target setting. Academy of Management Journal, 60(3), 1189-1211.

17. Niven, K., \& Healy, C. (2016). Susceptibility to the 'dark side' of goal-setting: Does moral justification influence the effect of goals on unethical behaviour? Journal of Business Ethics, 137(1), 115-127.

18. Schweitzer, M. E., Ordóńez, L., \& Douma, B. (2004). Goal setting as a motivator of unethical behavior. Academy of Management Journal, 47(3), 422-432.

19. Harms, R., Reschke, C. H., Kraus, S., \& Fink, M. (2010). Antecedents of innovation and growth: Analysing the impact of entrepreneurial orientation and goal-oriented management. International Journal of Technology Management, 52(1/2), 135-152.

20. Lindenberg, S., \& Foss, N. J. (2011). Managing joint production motivation: The role of goal framing and governance mechanisms. Academy of Management Review, 36(3), 500-525.

21. Bartkus, B. R., \& Glassman, M. (2008). Do firms practice what they preach? The relationship between mission statements and stakeholder management. Journal of Business Ethics, 83(2), 207-216.

22. Bart, C. K., Bontis, N., \& Taggar, S. (2001). A model of the impact of mission statements on firm performance. Management Decision, 39(1), 19-35.

23. Bartkus, B. R., \& Glassman, M. (2008). Do firms practice what they preach? The relationship between mission statements and stakeholder management. Journal of Business Ethics, 83(2), 207-216.

24. Kopaneva, I., \& Sias, P. M. (2015). Lost in translation: Employee and organizational constructions of mission and vision. Management Communication Quarterly, 29(3), 358-384.

25. Cardona, P., \& Rey, C. (2008). Management by missions. New York: Palgrave Macmillan.

26. Melé, D. (2005). Exploring the principle of subsidiarity in organisational forms. Journal of Business Ethics, 60(3), 293-305.

27. Hollensbe, E., Wookey, C., Hickey, L., George, G., \& Nichols, C. V. (2014). Organizations with purpose. Academy of Management Journal, 57(5), 1227-1234.

28. https://www.youtube.com/watch?v=aGaFeld7dGc. Retrieved January 30, 2019.

29. Ibidem.

30. https://labs.spotify.com/2014/03/27/spotify-engineering-culture-part-1/. Retrieved September 4, 2018.

31. Pires, J. F., Rey, C., Mas-Machuca, M., \& Bastons, M. (2016). Management by missions in the healthcare sector. Revista de Calidad Asistencial, 31(4), 239-242. 
32. https://www.youtube.com/watch?v=xI1Cg2FkrxM. Retrieved January 30, 2019.

33. Cardona, P., Rey, C., \& Carmona, P. H. (2012). Caso Repsol Portuguesa: cómo vencer la resistencia al cambio. Harvard Deusto Business Review, (212), 38-47.

34. Cardona, P., \& Rey, C. (2008). Management by missions. New York: Palgrave Macmillan.

35. https://www.youtube.com/user/catedraDpm/search?query=nalon. Retrieved November 3, 2018.

36. Hamel, G., \& Zanini, M. (2018). The end of bureaucracy. Harvard Business Review.

37. Rey, C., Chinchilla, N., \& Pitta, N. (2017). Objectives are SMART, missions are WISE: Employees with purpose, IESE Insight, No. 33, Second Quarter 2017, pp. 45-51.

38. Bernstein, E., Bunch, J., Canner, N., \& Lee, M. (2016). Beyond the holacracy hype. Harvard Business Review, 94(7), 8.

39. Fussell, C., \& Goodyear, C. W. (2017). One mission: How leaders build a team of teams. Penguin.

40. For the question on when and how managers must use legitimate power over self-managed work see: Klapper, H., \& Reitzig, M. (2018). On the effects of authority on peer motivation: Learning from Wikipedia. Strategic Management Journal.

41. https://www.youtube.com/watch?v=BWh4BCKvQaA. Retrieved January 30, 2019.

42. Hamel, G. (2012). What matters now: How to win in a world of relentless change, ferocious competition, and unstoppable innovation. John Wiley \& Sons.

43. Gulati, R. (2018). Structure that's not stifling. Harvard Business Review, 96(3), 68-79.

Open Access This chapter is licensed under the terms of the Creative Commons Attribution 4.0 International License (http://creativecommons.org/licenses/by/4.0/), which permits use, sharing, adaptation, distribution and reproduction in any medium or format, as long as you give appropriate credit to the original author(s) and the source, provide a link to the Creative Commons licence and indicate if changes were made.

The images or other third party material in this chapter are included in the chapter's Creative Commons licence, unless indicated otherwise in a credit line to the material. If material is not included in the chapter's Creative Commons licence and your intended use is not permitted by statutory regulation or exceeds the permitted use, you will need to obtain permission directly from the copyright holder. 